\title{
Análisis crítico de la representación informativa de Camila Vallejo y el Movimiento Estudiantil chileno 2011 en el diario Las Últimas Noticias
}

\author{
Pamela ROMERO LizAMA \\ Universidad Austral de Chile \\ pamelarome@gmail.com
}

Recibido: $18 / 02 / 2013$

Aceptado: 09/09/2013

\section{Resumen}

El presente trabajo desarrolla un análisis crítico del tratamiento informativo que realizó el periódico "La Últimas Noticias" al Movimiento Estudiantil 2011 en Chile, por medio de la figura de una de sus líderes, Camila Vallejo. Se hace una reflexión en torno al poder de construcción de realidad social que tienen los medios de comunicación y a la influencia de los contenidos ideológicos en las entregas noticiosas. Palabras clave: Chile; movimiento estudiantil; medios de comunicación; análisis crítico; Camila Vallejo

\section{Critical analysis of the informative representation of Camila Vallejo and the} Chilean Student Movement 2011 in the newspaper Las Últimas Noticias

\begin{abstract}
This paper develops a critical analysis of news coverage conducted by the newspaper Las últimas noticias of the Student Movement of 2011, in Chile, through the figure of one of their leaders, Camila Vallejo. It is a reflection on the power of social construction of reality held by the media and the influence of ideological content in the news.
\end{abstract}

Keywords: Chile; students movement, media, critical analysis Camila Vallejo

\section{Referencia normalizada}

ROMERO LIZAMA, Paloma (2013): "Análisis crítico de la representación informativa de Camila Vallejo y el Movimiento Estudiantil chileno 2011 en el diario Las Últimas Noticias “. Estudios sobre el Mensaje Periodístico. Vol. 19, Núm. 2 (julio-diciembre), págs.: 871-888. Madrid, Servicio de Publicaciones de la Universidad Complutense.

Sumario: 1. Introducción. 2. La noticia entendida como discurso público. 3. La construcción de la noticia y el trabajo periodístico. 4. La construcción noticiosa de la realidad social. 5. Análisis; 5.1. Análisis contextual; 5.1.1. El diario Las Últimas Noticias; 5.1.2. El Movimiento Estudiantil 2011 en Chile; 5.1.3. El Domingo Familiar por la Educación; 5.2. Análisis textual; 5.2.1. Situación discursiva; 5.2.2. Macroestructuras temáticas; 5.2.3. Significados locales; 5.2.4. Estructuras sutiles. 6. Conclusiones. 7. Referencias. 8. Anexos.

\section{Introducción}

El único héroe válido es el héroe "en grupo". Nunca el héroe individual, el héroe solo. Héctor Germán Oesterheld

Los medios de comunicación encarnan una herramienta poderosa para la propagación de ideologías: creencias, maneras de ver al otro, modos de concebir la realidad social y económica. Por su parte, los lectores parecen haber entendido que tienen que estar más reacios a aceptar cualquier discurso periodístico como la verdad, poniendo bajo 
sospecha a los medios y dudando de sus intenciones, aunque sin entender con claridad de qué manera la información puede ser manipulada.

En este trabajo se hace un análisis crítico de la representación informativa e ideológica del diario Las últimas noticias, que involucra directamente a la líder del Movimiento Estudiantil 2011 en Chile, Camila Vallejo': la bullada portada (ver 8. Anexos) que tituló, el 22 de agosto de 2011, "Camila Vallejo no quiso mover la colita". El día anterior se había realizado una multitudinaria marcha familiar por la educación y un acto artístico en el que músicos, actores y estudiantes se habían congregado para dar señales de su descontento con las formas de conducir la educación en Chile.

En esta coyuntura, cabe preguntarse ¿por qué temas serios cómo la política o la educación aparecen en un diario de entretenimiento como Las últimas noticias, y, más aún, en primera plana? ¿Cómo son representados los líderes del Movimiento Estudiantil 2011 y el propio movimiento?

Por medio de esta investigación se buscará desenmascarar las estrategias textuales y contextuales con las que Las últimas noticias intentó farandulizar al Movimiento Estudiantil, restándole importancia a la discusión pública, por medio de un ataque personal sexista a Camila Vallejo, Presidenta de la Federación de Estudiantes de la Universidad de Chile (FECH) durante el 2011. Esto, en el entendido de que los medios de comunicación burgueses promueven el discurso dominante, tanto económico como ideológico, que busca el disciplinamiento y el control social.

\section{La noticia entendida como discurso público}

¿Por qué es importante estudiar las noticias como discursos públicos? Principalmente porque son concebidas como una radiografía de la actualidad. Son discursos de algunos (subjetividades) que se hacen públicos para todos (objetividades). Para Teun van Dijk, las noticias son producciones discursivas de gran relevancia y es necesario ahondar en sus contenidos y repercusiones, ya que:

La mayor parte de nuestro conocimiento social y político, así como nuestras creencias sobre el mundo, emanan de las decenas de informaciones que leemos o escuchamos a diario. Es muy probable que no exista ninguna otra práctica discursiva, aparte de la conversación cotidiana, que se practique con tanta frecuencia y por tanta gente como son el seguimiento de las noticias en prensa y televisión (van Dijk, 1997: 29).

Mientras que el común de las personas solamente domina los discursos emitidos por ellos mismos (en sus conversaciones cotidianas), las elites tienen acceso a expresarse por distintos canales, controlando, por ejemplo, el discurso gubernamental y mediático, entre los más importantes. Éste es el sentido con el que se deben recibir las noticias hoy en día, entendiéndolas según sus nexos con las ideologías y con el poder.

1 Camila Vallejo Dowling (Santiago de Chile, 28 de abril de 1988), estudiante de Geografía de la Universidad de Chile, militante de la Juventudes Comunistas de Chile. Entre los años 2010 y 2011 fue la segunda mujer electa presidenta de la FECH (Federación de Estudiantes de la Universidad de Chile), lo que la convirtió en la líder principal del Movimiento Estudiantil Universitario chileno 2011 y de la CONFECH (Confederación de Estudiantes de Chile). 
La prensa ha ido mutando en una balanza que se carga siempre hacia las voces dominantes, ya sea de los representantes de la política, como del poder económico. Es una problemática que transita entre tres aristas: la cultura, la política y la economía.

$\mathrm{Al}$ asumir que los medios de comunicación están ligados a grupos de poder, se entiende que esos grupos cuentan con mayor facilidad para difundir sus creencias, intereses y valores (ideología), y, por tanto, a someter las mentes y las acciones de aquellos a quienes llegan los discursos. Este es el problema fundamental, ya que se facilitan las condiciones para cometer abusos, basados en la tarea mesiánica de los medios, cuyo rol de informar (legitimado socialmente) significa una fuente de veracidad para los individuos.

Esta verdad objetiva se relaciona a los orígenes de la profesión, una digna hija del racionalismo ilustrado: "el periodismo se articula y desarrolla en el marco del cientificismo objetivista [...] Del ideal cientificista deriva, también, la falacia de la objetividad informativa" (Vázquez Medel, 1998). En este juego de roles, el periodista desempeña un papel fundamental: se le atribuye la competencia para seleccionar los acontecimientos importantes y convertirlos en noticia. Está inmerso en la sociedad, interactúa con otros, pero enfrenta la realidad simultáneamente como participante y observador (crítico), articulando ideas, vinculando hechos y contextos, produciendo discursos noticiosos y dotándolos de significaciones (Vera, 2008: 296). Es un mediador entre el público y la realidad social.

En palabras de Miquel Rodrigo (2005: 13): "Los periodistas son, como todas las personas, constructores de la realidad de su entorno. Pero además dan forma de narración a esta realidad y, difundiéndola, la convierten en una realidad pública". Las noticias se sustentan en reafirmaciones de creencias compartidas socialmente, y estas creencias, a su vez, se legitiman (en gran medida) por medio de su aparición en los discursos periodísticos, y se va así (re)construyendo la realidad.

Simplificando el funcionamiento de los medios, podemos situarnos en un esquema de producción, en el que los acontecimientos ingresan a los medios de comunicación como inputs (información recibida). Por su parte, los medios producen outputs, que son las noticias, es decir, la información procesada institucionalmente. Pero estas noticias son recibidas por los lectores con apariencia de acontecimientos objetivos. De esta manera, la etapa de la elaboración de la noticia permanece oculta al público (Rodrigo Alsina, 2005).

A pesar de las buenas (o viciadas) intenciones de los reporteros, es innegable la influencia que tiene el ejercicio del periodismo en el traspaso de ciertas ideologías por sobre otras. Pero no se debe olvidar que el periodista no es independiente del medio en el que trabaja. Hay toda una trama de estructuras que dominan la producción informativa. Ésta "debe interpretarse desde el concepto de relaciones de poder que afectan su funcionamiento, y que establecen una noción predominante sobre el interés público y la orientación de las discusiones trascendentes" (Arrueta, 2010: 226).

Hay en los medios de comunicación un arma de doble filo: por un lado, una herramienta de dominación de unos sobre otros a través de la imposición de ideologías. Por el otro, una potencialidad inmensa que todavía no ha sido desarrollada completamente, liberadora, transformadora: la actividad periodística tiene vocación social, es 
un instrumento de denuncia y activador de cambios profundos (Vázquez Medel, 1998). Tiene el poder para legitimar una problemática social, como para espectacularizarla o convertirla en producto de consumo (Ossa, 2003).

Se hace necesario acercarse a las noticias en su constitución, un acercamiento cualitativo que entregue mayor profundidad que el análisis de contenido, pues “... las estructuras de las noticias pueden relacionarse explícitamente con las prácticas sociales y con las ideologías de producción de noticias e, indirectamente, con los contextos institucional y macrosociológico de los medios periodísticos" (van Dijk, 1990: 09).

Es indispensable cuestionarse de qué forma una noticia (de prensa escrita, en este caso) es construida por los periodistas y en qué medida estas estrategias de redacción pueden servirnos para develar los sistemas de poder y las ideologías presentes en el discurso noticioso, tanto en el texto en sí, como en el contexto al que se alude.

\section{La construcción de la noticia y el trabajo periodístico}

¿Qué entendemos por noticia? Podemos encontrar diferentes definiciones: un hecho actual, desconocido e inédito; nueva información de interés general, escrito breve, veraz y oportuno (objetivo); etc. Básicamente, la noticia es el género fundamental del periodismo. Pero hablar de las noticias no es hablar de la realidad tal cual es. Hablar de las noticias es hablar de una realidad filtrada, digerida y construida: producida para el consumo de un público específico. Para entender el proceso de construcción de una noticia es necesario transparentar y simplificar el funcionamiento de los medios de comunicación.

La construcción de una noticia da inicio con el acontecimiento, que es la materia prima de la noticia. El acontecimiento se relaciona a la lectura contextualizada de la realidad que hace un determinado sujeto. Es ajeno al sujeto, porque tiene que ver con circunstancias de la realidad social que él no domina, pero está profundamente determinado por dicho sujeto, ya que es él quien le provee de sentido a estos fenómenos, dando paso a un acontecimiento. El sujeto observador (el periodista) es quien da sentido, valoración e importancia a éste, al interpretarlo.

En la prensa escrita (nuestro caso de estudio), las noticias son el principal formato en el que la información es entregada (discurso periodístico). Éstas se redactan generalmente de una determinada manera, que le brinda una estructura diferente de lo que podrían ser otro tipo de discursos (como los textos narrativos, descriptivos o argumentativos, entre otros).

Una noticia se escribe siguiendo una fórmula básica, conocida como "Pirámide Invertida". En esta estructura, los contenidos más importantes van en la parte superior, y a medida que vamos descendiendo, se llega a la información menos relevante. En la parte superior de la pirámide noticiosa encontramos el titular: Epígrafe, Título, Bajada. Al analizar la estructura de la noticia, esta sección es importante, ya que se entrega una síntesis resumida del contenido de la noticia. Dicho contenido se traduce y se localiza fácilmente en las macroestructuras semánticas (tópicos) de los textos informativos (van Dijk, 1990).

Las noticias son escritas en tercera persona (singular), con oraciones breves, claras y sencillas y párrafos cortos, que faciliten la lectura, dado el amplio público al que 
se pretende llegar. $\mathrm{Al}$ interior del texto, el periodista debe responder a las siguientes preguntas (6W): ¿Qué? El hecho; ¿Quién, Quiénes? El sujeto; ¿Cuándo? El tiempo; ¿Dónde? El lugar; ¿Cómo? El proceso; y ¿Por qué? La finalidad.

En un sentido práctico, esta modalidad de escritura es útil cuando los editores deben cortar un texto para acomodarlo a una determinada página dentro de la publicación, y así no se pierden los datos fundamentales. Se entiende entonces que "El discurso informativo supone la reducción de la riqueza expresiva del lenguaje, en función de las posibilidades de transmisión rápida y difusión masiva de las noticias" (Schanider y Zarowsky, 2007: 147).

Al haber conocido de manera resumida el trabajo periodístico, es más sencillo comprender la gran influencia que tiene el actuar de los medios de comunicación en el traspaso de ciertos tipos de saberes e ideologías por sobre otros, ya que:

...la producción de textos informativos es esencialmente un proceso de reconstrucción en el que la selección, exclusión y resumen desempeñan un importante papel. Por supuesto, estos procesos están, al mismo tiempo, controlados por el conocimiento, las creencias u otras cogniciones sociales de los periodistas entre las que se cuentan sus actitudes políticas y también el reglamento profesional, las estrategias y los valores informativos generales (van Dijk, 1997: 68).

\section{La construcción noticiosa de la realidad social}

Por un lado, se entiende que la realidad es construida socialmente (Berger y Luckmann, 2011) a partir de las diversas informaciones que recibimos. Cada individuo construye, concibe su propia realidad subjetiva a partir de sus percepciones sobre lo que lo rodea, ya sea basado en sus propias experiencias, como en fuentes informativas indirectas, como los medios de comunicación. Por otro lado, los individuos, a su vez, son construidos y modelados por esta realidad social.

Hablamos de una continuidad dialéctica en la que se relacionan el hombre (en colectivo), el productor, y el mundo social (su producto), que más tarde vuelve a actuar sobre su productor. También se puede llamar a esta continuidad "círculo creativo" o "virtuoso", desde la perspectiva reflexiva celular de Francisco Varela (2005: 251), en el sentido en que se presentan diversos elementos y operaciones que confluyen en un círculo cerrado en el que se (con)funden, y en “... el cual los productos se encuentran en el mismo plano que los procesos de producción. Dentro de esta organización pierden sentido las diferenciaciones usuales entre productor y producto, entre comienzo y final" (2005: 253).

Berger y Luckmann advierten en esta relación tres momentos (dialécticos y característicos) de la realidad social: "La sociedad es un producto humano. La sociedad es una realidad objetiva. El hombre es un producto social" (Berger y Luckmann, 2011: 82). Éste es un proceso del que no somos conscientes, pero cuya visibilidad aportaría mucho para comprender y mejorar las relaciones en sociedad: somos (en grupo) también responsables por la construcción de nuestra realidad (colectiva).

Esto nos permite insertar el funcionamiento de los medios de comunicación en un sistema más amplio de construcción y transmisión de significaciones, en el que se entiende la realidad social como una construcción noticiosa. Los acontecimientos son ex- 
traídos de la realidad social, y pasan a través de los medios de comunicación, para salir convertidos en noticias. Por su parte, las noticias influyen en los individuos, quienes construyen su realidad social a través de ellas. Considerando este último punto, se hace necesario reflexionar cómo los diferentes discursos presentados en los medios contribuyen a la reproducción de las desigualdades y al abuso de poder (o los combaten) y cuáles son sus tácticas de acción.

Como es sabido, a partir de las informaciones emitidas por los medios de comunicación (y activadas a partir de éstas en los lectores) es posible la transmisión de aparatos ideológicos invisibles, que no son percibidos a primera vista. De esta manera, los periodistas y los medios van modelando y modificando la realidad a la que tiene acceso el público. En este sentido, quien tiene mayor información, tiene un mayor poder. Y quien tiene control sobre la información que se transmite a los demás, tiene un poder incluso mayor.

Las clases sociales dominantes, por tanto, se verían favorecidas en dos aspectos fundamentales: a) al tener una mayor educación y experiencia cultural (que otorgan poder), aprovecharían de mejor manera la información recibida de los medios de comunicación; y b) son ellos quienes tiene el control económico e ideológico sobre los medios de comunicación, por tanto deciden qué (temas) y quiénes (actores y fuentes) aparecen en las entregas informativas. En directa relación al segundo aspecto, se puede señalar que dichos medios de comunicación:

... pertenecen a la esfera de una ideología de clase dominante, y constituyen los soportes de la ideología llamada genéricamente burguesa. Por tanto, reflejarán "la visión del mundo" $[. .$.$] que tiene esta clase y que ella desea hacer aceptar como la única razonable,$ la única objetiva y, por consiguiente, la única universal. En la medida en que esta clase monopoliza los medios de producción y domina la estructura del poder de la información, será su visión particular del mundo, la que tenderá a imponerse como visión general de ese mismo mundo (Mattelart, Piccini y Mattelart, 1976: 24).

Al reflexionar en torno a la confusión (intencionada) y al aletargamiento producido por los medios de comunicación en la "aldea global", que entienden la información como una mercancía (y no como un derecho), Ryszard Kapuściński plantea la siguiente analogía: "En una dictadura, se recurre a la censura; en una democracia, a la manipulación. El blanco de las agresiones es siempre el mismo: el ciudadano medio" (2003: 25). Para Kapuściński, los medios han perdido su vocación social y prestan más atención a los aspectos técnicos, políticos y económicos que a los aspectos humanos, reflejando la realidad del mundo de manera muy superficial y fragmentaria, según la conveniencia de las empresas informativas.

Por otro lado, Pascual Serrano hace hincapié en la paradoja de haber puesto ciega confianza en los medios de comunicación como vigilantes del sistema: "Lo que alguna vez se llamó «El Cuarto Poder», por considerarlo el más adecuado para controlar a los otros tres en nombre de la ciudadanía, ha terminado siendo más poderoso, menos controlable democráticamente y menos representativo" (2011: 35). Por tanto, aún quedan preguntas por responder, como ¿quién vigila a la prensa?, ¿quién vigila a los vigilantes?, ¿quién fiscaliza a los medios de comunicación? 


\section{Análisis}

Apostando por la perspectiva metodológico-hermenéutica brindada por los estudios del Análisis Crítico del Discurso, y principalmente en relación a los trabajos de Teun van Dijk (1990, 1997 y 2003), se realizó un estudio de caso centrado en el texto y en el contexto de la noticia. Se seleccionó la portada y noticia en cuestión (22 de agosto de 2011, diario Las últimas noticias), ya que es considerada como emblemática dentro de la cobertura mediática al Movimiento Estudiantil 2011 en Chile.

Según Van Dijk, la principal forma de control social y abuso de poder se presenta cuando un grupo dominante tiene el manejo de los discursos, ya que, además de influir en el contexto, se ejerce un poder sobre el texto (y el habla) de los dominados. Esto se entiende debido a que el acceso a los tipos de discurso es muy limitado y va ligado directamente al poder social (van Dijk, 1997). De esta manera, el Análisis Crítico del Discurso se presenta como una alternativa para conocer cómo se expresa esta dominación por medio de los textos informativos. Vale decir, “... cómo se relacionan las ideologías con las relaciones cognitivas que subyacen en la producción y la comprensión de la noticia" (van Dijk, 1990: 259).

\subsection{Análisis contextual}

\subsubsection{EI diario Las Últimas Noticias}

La portada y noticia analizadas aparecieron en la publicación № 36.365 del diario Las últimas noticias, correspondiente al lunes 22 de agosto del 2011. La cobertura al acto Familiar por la Educación abarca (incluyendo la portada) de las páginas 24 a la 26.

Las últimas noticias es un diario matutino chileno, de cobertura nacional, perteneciente al conglomerado de medios "El Mercurio Sociedad Anónima Periodística" y nacido en 1902. Su Director es Agustín Edwards del Río. Es reconocido por tratar informaciones referidas a la farándula local (prensa rosa) y al fútbol, aunque también cubre diferentes aristas noticiosas como política, economía y actualidad nacional e internacional. Ideológicamente, este periódico es de corte tradicionalista y conservador, respondiendo a patrones de la prensa burguesa controlada por la derecha chilena.

Para El Mercurio Media Center, Las últimas noticias se concibe a sí mismo como "un diario de lectura compartida y [...] una herramienta de socialización entre los chilenos. Nuestro desafío es llevar en la portada el tema de conversación del día. Es un diario contingente, liberal, diverso y tolerante"2.

Este diario es el segundo con mayor circulación en Chile y el primero más leído ${ }^{3}$ (tanto en formato papel como en digital), según Valida, en su Boletín de Circulación y Lectoría de Diarios, correspondiente al Primer Semestre del año 2012. Además, el sitio www.lun.cl (versión íntegra del diario) es el medio de comunicación chileno más visitado en internet ${ }^{4}$, ocupando, además, el puesto 10 dentro de los sitios más visita-

${ }^{2}$ Fuente: http://www.elmercuriomediacenter.cl/prensa/las-ultimas-noticias/diario/

${ }^{3}$ Fuente:http://www.valida-chile.cl/boletines/2012/1S/boletin_diarios\%20prim_sem_2012.pdf

${ }^{4}$ Según el ranking Alexa: http://www.alexa.com/topsites/countries/CL 
dos de Chile. Sus principales lectores pertenecen a los segmentos socioeconómicos medio y bajo (C3 y D, 73\%).

"El Mercurio Sociedad Anónima Periodística" (propiedad de Agustín Edwards Eastman) posee dos diarios de circulación nacional (El Mercurio y Las Últimas Noticias), dos que circulan en la región metropolitana y zona central (La Segunda y HoyxHoy, diario gratuito), además del sitio de noticias www.emol.com. Este conglomerado también es dueño de 21 diarios regionales, que circulan en las ciudades más importantes del país, y de las radios Digital FM y Positiva FM, ambas con filiales en todo Chile.

Cabe señalar que forma parte del gran duopolio de la prensa chilena en la actualidad (junto a Copesa ${ }^{6}$ ), y que, además, existen innumerables documentos y testimonios que prueban los montajes preparados por esta sociedad periodística para encubrir y justificar violaciones a los derechos humanos durante la Dictadura Militar en Chile?

\subsubsection{El Movimiento Estudiantil 2011 en Chile}

Durante abril y mayo de 2011 comenzaron a realizarse manifestaciones de estudiantes universitarios y secundarios en todo Chile. En ellas se exigía al gobierno un cambio radical en el sistema educacional. A esta contingencia se la ha denominado "Movimiento Estudiantil" y se enmarca dentro de un conjunto de prácticas de empoderamiento por parte de la sociedad civil, que ha sido conocido como "La Primavera de Chile".

Entre las principales demandas del movimiento se destacan el aumento del gasto público en educación, reformas al sistema de ingreso a las universidades, desmunicipalización y estatización de la enseñanza básica y secundaria, fin al lucro, calidad y gratuidad en todos los niveles de la educación, entre otras.

Las modalidades de acción y de concientización del movimiento han sido principalmente las asambleas, foros, debates, tomas y ocupaciones pacíficas de universidades, liceos, colegios y edificios públicos, paros, huelgas de hambre, cacerolazos, velatones, marchas ciudadanas y actos artístico-culturales (Garcés, 2012). En estas actividades se ha contado con el apoyo de profesores y académicos, padres y apoderados y diversas organizaciones sociales y gremiales que han acogido como suyas las solicitudes de los estudiantes.

Una de las principales características de los estudiantes movilizados es la creatividad: el movimiento estudiantil tiene, además de su obvio componente político-ideológico de izquierda, un dispositivo estético. Se reconoce la capacidad simbólica de

5 Fuente: http://www.elmercuriomediacenter.cl/wp-content/uploads/ESTUDIO-DE-LECTOR\%C3\%8DA-a-septiembre-2012.pdf

6 Consorcio Periodístico de Chile S.A.: http://www.copesa.cl/

7 Ver las investigaciones de académicos y periodistas de la Universidad de Chile en el libro El Diario de Agustín. Cinco estudios de casos sobre El Mercurio y los derechos humanos (1973-1990) de Claudia Lagos (Editora), publicado en LOM el año 2009. También se puede revisar el documental El Diario de Agustín de Ignacio Agüero y Fernando Villagrán (2008), en el que se sigue un registro del proceso investigativo de los autores del libro y las entrevistas realizadas. 
las imágenes, y la potencialidad de éstas se pone en escena en cada una de las actividades, que presentan un carácter performativo y visual:

"Más parecido a un "carnaval", en el sentido de Bajtín, que a la clásica protesta en las calles. Las manifestaciones estudiantiles se han vuelto fotogénicas y telegénicas [...] La acción política y la visualidad son, ahora, inseparables" (Cuadra, 2012: 09)

Los principales líderes del Movimiento Estudiantil Universitario 2011 fueron la presidenta de la FECH (Federación de Estudiantes de la Universidad de Chile) Camila Vallejo y Giorgio Jackson, presidente de la FEUC (Federación de Estudiantes de la Universidad Católica de Chile). Con relación a su experiencia como importante figura estudiantil, Camila Vallejo señala sentirse orgullosa del movimiento porque “... mucha gente se ha integrado a él y ha logrado [...] hacer un cuestionamiento de fondo al actual modelo, ya no solamente en el ámbito de la educación, sino a nivel [...] de un modelo de desarrollo que produce desigualdad en la educación y en otras áreas" (2012: 5). Siguiendo esa línea, Vallejo no duda en recalcar que:

Chile no va a transformar de raíz su educación si no enmarca esta lucha en una gran batalla por erradicar todo rezago autoritario, antidemocrático y mercantil de todo ámbito social, político y económico. La educación emancipadora, igualitaria y liberadora será un primer puente entre el pueblo y la construcción de su destino (2012: 132).

Pero también es importante advertir que el Movimiento Estudiantil 2011 en Chile no debe reducirse a la figura de sus líderes (si bien puede medirse a través de ellos), ni tampoco es correcto idealizarlos. Más allá de quienes fueron elegidos por las organizaciones, están las voces y las realidades de los otros, los invisibles, olvidados, relegados por un sistema económico injusto y que les niega las oportunidades para desarrollar a cabalidad sus capacidades:

[a su lado] “... están las siluetas de miles de niños de familias pobres que esperan mucho más de su país le confiere a las protestas estudiantiles una estatura moral que no hemos visto en el país por varias décadas" (Cuadra, 2012: 61).

\subsubsection{El Domingo Familiar por la Educación}

El domingo 21 de agosto de 2011 se desarrolló un Gran Acto Familiar por la Educación denominado "Marcha de Remolinos y Recital por la Educación", convocado por actores sociales y artistas. El evento se llevó a cabo en el Parque O'Higgins, y reunió a conocidos líderes políticos y sociales, actores y músicos. Pasadas las 10 de la mañana comenzaron dos marchas distintas (profesores y trabajadores desde Alameda con Avenida España y estudiantes y apoderados desde Vicuña Mackenna con Avenida Matta) que confluyeron en el parque, dando paso a un gran acto cultural a eso de las 13:00 horas.

Los organizadores cifraron en más de un millón ${ }^{8}$ los asistentes al acto, pero según Carabineros y la Intendencia Metropolitana, la convocatoria fue de 100 mil. Durante este Domingo Familiar por la Educación no hubo detenidos ni incidentes9.

8 Fuente: http://radio.uchile.cl/noticias/119346/

9 Fuente: http://www.lanacion.cl/noticias/site/artic/20110821/pags/20110821211835.html 
Considerando los antecedentes anteriores, y en relación a la cobertura mediática del evento, la portada de Las Ultimas Noticias no pasó inadvertida para nadie. Diversas entidades abocadas a estudios de género y equidad ${ }^{10}$ en el sistema informativo ${ }^{11}$ manifestaron su malestar. La misma FECH, por medio de su cuenta de Facebook ${ }^{12}$, declaró públicamente su indignación el día 22 de agosto de 2011, a través del siguiente texto:

La portada de LUN es deplorable:

1) Agrede al movimiento: habiendo tantas cosas lindas que mostrar sobre el acto familiar, político, social y artístico saca una portada de carácter sexista, con 0 relación con lo vivido ayer.

2) Agrede a Camila Vallejo: ella es una de las dirigentes del movimiento, no es una modelito de discotheque.

3) Agrede a las mujeres: todas las mujeres, estén de acuerdo o no con el movimiento, nos vemos ofendidas, porque con esta portada reducen a la mujer a un objeto.

\subsection{Análisis textual}

\subsubsection{Situación discursiva}

Para un primer acercamiento al discurso noticioso, se vuelve útil una descripción de los aspectos funcionales del texto a analizar, por lo que se identificarán los componentes de la situación discursiva. Un modelo fundamental para develar y aclarar los factores que intervienen en esta situación comunicativa es el que plantea Dell Hymes. A continuación, se presenta su aplicación ${ }^{13}$ :

\begin{tabular}{|c|l|}
\hline MODELO SPEAKING \\
\hline SITUACIÓN & $\begin{array}{l}\text {-Tiempo: Lunes 22 de agosto de } 2011 . \\
\text {-Lugar: Diario Las Últimas Noticias. }\end{array}$ \\
\hline ESCENA & $\begin{array}{l}\text { Las Últimas Noticias es un diario chileno, de cobertura nacional, } \\
\text { perteneciente al conglomerado periodístico El Mercurio S. A. P. Es } \\
\text { el diario más leído del país }\end{array}$ \\
\hline
\end{tabular}

${ }^{10}$ Ver columna de opinión de Natalia Flores, Tatiana Hernández y Cristián Cuevas, del Observatorio de Género y Equidad, titulada "¿Cómo se llama la obra?: Camila Vallejo en tres actos". Fuente: http://www.observatoriogeneroyliderazgo.cl/index.php/las-noticias/4865icomo-se-llama-la-obra-camila-vallejo-en-tres-actos

${ }^{11}$ Por ejemplo, 19 académicos del Instituto de la Comunicación e Imagen de la Universidad de Chile (ICEI) presentaron una denuncia ante el Tribunal de Ética del Consejo Metropolitano del Colegio de Periodistas. Fuente: http://www.icei.uchile.cl/noticias/75882/colegiode-periodistas-condena-discriminacion-de-lun-a-presidenta-fech

${ }^{12}$ Fuente: https://www.facebook.com/pages/FECH-Federaci\%C3\%B3n-de-Estudiantes-de-laUniversidad-de-Chile/129476138947

${ }^{13}$ Versión del modelo SPEAKING de Dell Hymes adaptada al español y presentada en el libro Introducción a los Estudios sobre el discurso de Jan Renkema (Gedisa, 1999: 63).

${ }^{14}$ Fuente:http://www.valida-chile.cl/boletines/2012/1S/boletin_diarios\%20prim_sem_2012.pdf 


\begin{tabular}{|c|c|}
\hline PARTICIPANTES & $\begin{array}{l}\text {-Emisor: Andrea Navarro (Periodista). } \\
\text {-Receptor: Lectores del diario Las Últimas Noticias. } \\
\text {-Actores: Camila Vallejo, FECH, estudiantes, Daniel Alcaíno, } \\
\text { público masculino, asistentes, multitud, políticos, conflicto } \\
\text { estudiantil, Giorgio Jackson, FEUC, CONFECH, trabajadores, } \\
\text { gobierno, Chico Trujillo, Los Tres. } \\
\text {-Fuentes: Camila Vallejo, Daniel Alcaíno, Giorgio Jackson. }\end{array}$ \\
\hline FINES & $\begin{array}{l}\text {-Objetivos: Informar acerca del actuar de la líder estudiantil Camila } \\
\text { Vallejo durante el evento Domingo Familiar por la Educación, } \\
\text { realizado en el Parque O’Higgins el día } 21 \text { de agosto de } 2011 . \\
\text {-Efectos: Se da un tratamiento sexista a la noticia (que además } \\
\text { conforma la portada del diario en su edición № } 36.365 \text { ), lo que } \\
\text { genera malestar en la Federación de Estudiantes de la Universidad } \\
\text { de Chile (FECH) }{ }^{15} \text {. }\end{array}$ \\
\hline $\begin{array}{c}\text { SECUENCIA DEL } \\
\text { ACTO }\end{array}$ & $\begin{array}{l}\text { El texto informativo se destaca en la portada, como contenido } \\
\text { principal del diario bajo el siguiente titular: "Camila Vallejo no } \\
\text { quiso mover la colita", acompañada de una fotografía en plano } \\
\text { medio de la líder estudiantil durante su discurso. La información } \\
\text { relacionada al Domingo Familiar por la Educación se distribuye } \\
\text { entre las páginas } 24 \text { a la } 26 \text {. En la página } 24 \text { se encuentra la noticia } \\
\text { principal, que lleva el siguiente titular: "Pese al clamor popular, } \\
\text { Camila Vallejo se negó a bailar la colita". La información se } \\
\text { acompaña de dos fotografías, una de Camila Vallejo en plano } \\
\text { americano, y otra más pequeña que muestra parte del público } \\
\text { asistente }\end{array}$ \\
\hline TONO & $\begin{array}{l}\text { La noticia se presenta con poca seriedad, banalizando a la líder y al } \\
\text { movimiento estudiantil. }\end{array}$ \\
\hline INSTRUMENTAL & Verbal: Se utiliza el español chileno en un modo coloquial. \\
\hline NORMAS & $\begin{array}{l}\text { El funcionamiento de los medios de comunicación burgueses } \\
\text { masivos y tradicionales, como los diarios impresos, es de carácter } \\
\text { vertical, hay posibilidades de interacción solamente en una } \\
\text { dirección. Se limita la acción del receptor a la de un simple } \\
\text { lector/consumidor. }\end{array}$ \\
\hline GÉNEROS & Noticia, Género informativo. \\
\hline
\end{tabular}

\subsubsection{Macroestructuras temáticas}

Para tener una idea general del texto a analizar, van Dijk (1990) recomienda hacer una revisión esquemática del texto noticioso, haciendo un resumen de los tópicos principales del texto. En primer lugar, se entiende que en los titulares de la noticia es posible acceder a los temas principales (según la "Pirámide Invertida"), por lo que es importante tener en cuenta estos elementos. Además, cabe recordar que esta noticia fue portada del diario.

\begin{tabular}{|c|l|}
\hline PORTADA DIARIO \\
\hline EPÍGRAFE & $\begin{array}{l}\text { Estudiantes desbordaron la elipse del Parque O'Higgins y dejaron } \\
\text { chico a Lollapalooza }\end{array}$ \\
\hline TÍTULO & Camila Vallejo no quiso mover la colita \\
\hline
\end{tabular}

${ }^{15}$ Fuente: http://www.cooperativa.cl/fech-repudio-sexista-portada-sobre-camila-vallejo/prontus nots/2011-08-22/124524.html 


\begin{tabular}{|l|l|}
\hline \multicolumn{1}{|c|}{ TITULAR NOTICIA } \\
\hline EPÍGRAFE & $\begin{array}{l}\text { Le gritaron que estaba "más rica que el pan con pebre", pero ni se } \\
\text { inmutó }\end{array}$ \\
\hline TÍTULO & $\begin{array}{l}\text { Pese al clamor popular, Camila Vallejo se negó a bailar la colita } \\
\text { BaJAdenta de la FECH llegó con una polera roja y jeans ajustados al } \\
\text { Domingo Familiar. De pasada anunció que los estudiantes se pliegan a } \\
\text { paro. }\end{array}$ \\
\hline
\end{tabular}

Aquí podemos interpretar que el tema principal de la noticia es que la líder estudiantil Camila Vallejo no quiso bailar "la colita"16 en un masivo acto familiar por la educación. Vallejo vestía ropa ajustada y recibió "piropos"

En segundo lugar, es necesario hacer una revisión fragmentada del texto en diferentes niveles estructurales, por lo que un primer paso es asignar una macropoposición por cada párrafo de la noticia. Una macroporposición es una proposición de carácter subjetivo, que es deducida estratégicamente por el lector, a modo de resumen del texto abordado (también son conocidos como los significados globales). En nuestro caso de análisis, sería de la siguiente manera:

\begin{tabular}{|c|c|}
\hline \multicolumn{2}{|r|}{ PROPOSICIONES POR PÁRRAFO } \\
\hline P1 & $\begin{array}{l}\text { Camila Vallejo, presidenta de la FECH, fue presentada y recibida como una gran } \\
\text { figura en el acto Domingo Familiar por la Educación en el Parque O'Higgins. }\end{array}$ \\
\hline $\mathbf{P 2}$ & $\begin{array}{l}\text { Camila Vallejo se vistió con ropa ajustada por altas temperaturas, lo que hizo que el } \\
\text { público masculino le gritara "piropos". }\end{array}$ \\
\hline P3 & $\begin{array}{l}\text { Le pidieron que bailara "la colita", pero Camila Vallejo ignoró la solicitud y } \\
\text { comenzó su discurso. }\end{array}$ \\
\hline P4 & Camila Vallejo dijo que los estudiantes querían ser escuchados. \\
\hline P5 & $\begin{array}{l}\text { Camila Vallejo y Giorgio Jackson (presidente de la FEUC) llegaron tarde al evento, } \\
\text { pues habían participado en una sesión de la CONFECH en Copiapó. }\end{array}$ \\
\hline P6 & $\begin{array}{l}\text { Giorgio Jackson dijo que la última propuesta del gobierno mantiene el } \\
\text { endeudamiento y no es el cambio que Chile pide, y luego bailó. }\end{array}$ \\
\hline P7 & Camila Vallejo estaba feliz con la convocatoria del evento. \\
\hline P8 & Camila Vallejo dijo que los estudiantes seguirán con las movilizaciones. \\
\hline
\end{tabular}

A partir de aquí, se buscan temas en común, convergencias entre los párrafos, para reducir a un siguiente nivel el resumen de significados.

\begin{tabular}{|l|ll|}
\hline M1 & P1+P2+P3 & $\begin{array}{l}\text { MACROPROPOSICIONES } \\
\text { Camila Vallejo fue recibida con "piropos" pero no quiso bailar "la } \\
\text { colita" en un acto por la Educación. }\end{array}$ \\
\hline M2 & P5+P6 & $\begin{array}{l}\text { Camila Vallejo estaba con Giorgio Jackson, quien criticó al } \\
\text { gobierno. }\end{array}$ \\
\hline M3 & P4+P7+P8 & $\begin{array}{l}\text { Camila Vallejo estaba feliz y dijo que los estudiantes seguirán } \\
\text { movilizados hasta ser escuchados. }\end{array}$
\end{tabular}

16 "La Colita" es una canción popularizada en Chile por el programa de variedades "Sábado Gigante". La letra es la siguiente: "Así, así, como mueve la colita. Si no la mueve la tiene tapadita".

${ }^{17}$ En el lenguaje coloquial de Chile se denomina "piropos" a las frases pícaras halagadoras hacia una mujer u hombre, en relación a su aspecto físico. 
Teniendo estas tres macroproposiciones es posible llegar al nivel más alto de resumen del texto periodístico, que sería el siguiente (y que se relaciona directamente al tema que se pudo dilucidar por medio del titular de esta noticia):

\section{TEMA}

Camila Vallejo no quiso bailar "la colita" y dijo que los estudiantes seguirán movilizados.

\subsubsection{Significados locales}

En el caso de los significados locales del texto, estos hacen relación al significar de las frases o proposiciones. Los de carácter explícito son aquellos que se pueden encontrar con claridad en las palabras del texto, y los implícitos son aquellos que se pueden inferir a través de las proposiciones o estrategias léxicas utilizadas por los redactores.

\begin{tabular}{|c|c|}
\hline \multicolumn{2}{|r|}{ SIGNIFICADOS LOCALES EXPLÍCITOS } \\
\hline SLE1 & $\begin{array}{l}\text { "Cuando el actor Daniel Alcaíno presentó a Camila Vallejo [...] parecía un } \\
\text { calcetinero más de la universitaria" (P1): En Chile, se llamaba "calcetineras" a las } \\
\text { fanáticas incondicionales de ídolos musicales o actores. Este término se relacionó } \\
\text { especialmente a la Nueva Ola musical de los años } 60 \text { y } 70 \text {. Se utiliza de manera } \\
\text { coloquial y, muchas veces, despectiva. }\end{array}$ \\
\hline SLE2 & $\begin{array}{l}\text { "La muchacha parecía rockstar" (P1): "Rockstar" son las estrellas de rock, } \\
\text { músicos o vocalistas de bandas que tienen gran éxito, tanto en popularidad como } \\
\text { en el ámbito económico. Llevan estilos de vida excéntricos. Esta caracterización } \\
\text { de Camila Vallejo como rockstar es complementaria con el SLE1 y el SLI1. }\end{array}$ \\
\hline SLE3 & $\begin{array}{l}\text { “.. antes de lanzar su carga contra los políticos" (P3): Se señala que Camila } \\
\text { Vallejo ataca directamente a los políticos en su discurso. }\end{array}$ \\
\hline SLE4 & $\begin{array}{l}\text { “.. el interminable conflicto estudiantil" (P3): Se caracteriza al conflicto } \\
\text { estudiantil como "interminable", como un problema que no tiene solución. }\end{array}$ \\
\hline
\end{tabular}

\begin{tabular}{|c|c|}
\hline \multicolumn{2}{|r|}{ SIGNIFICADOS LOCALES IMPLÍCITOS } \\
\hline SLI1 & $\begin{array}{l}\text { "Estudiantes [...] dejaron chico a Lollapalooza" (Epígrafe portada): Se } \\
\text { faranduliza al movimiento estudiantil, al ponerlo a la par con la convocatoria de } \\
\text { un evento musical desideologizado. Si bien se destaca su masividad, se pretende } \\
\text { banalizarlo, restándole seriedad y el componente político. }\end{array}$ \\
\hline SLI2 & $\begin{array}{l}\text { "Pese al clamor popular, Camila Vallejo se negó a bailar la colita" (Título } \\
\text { noticia): Se puede inferir que como Camila Vallejo tiene una ideología de } \\
\text { izquierda (Juventudes Comunistas), se hace énfasis al carácter "popular" de la } \\
\text { petición a la que se negó. Se deja entrever que si Vallejo fuera consecuente con su } \\
\text { postura "popular", tendría que haber bailado "la colita" para el pueblo y para los } \\
\text { estudiantes. }\end{array}$ \\
\hline SLI3 & $\begin{array}{l}\text { "... un calcetinero más de la universitaria"; "La muchacha parecía rockstar" (P1): } \\
\text { Se asocia a Camila con tópicos de juventud, que hacen relación a una persona no- } \\
\text { completa: Camila no es un adulto formado, es "universitaria"; no es una mujer } \\
\text { aún, es una "muchacha". }\end{array}$ \\
\hline SLI4 & $\begin{array}{l}\text { "El sol, aliado de ellos, además dejaba ver a una Camila no tan abrigada, vestida } \\
\text { con una polera roja que destacaba su delgada figura, un ajustado jeans y su } \\
\text { infaltable banano. Camila tomó el micrófono, saludó y los piropos brotaron casi } \\
\text { adelantando la primavera" (P2): Se responsabiliza a Camila Vallejo por vestir } \\
\text { ropa ajustada para recibir piropos intencionalmente. }\end{array}$ \\
\hline
\end{tabular}




SLI5 "Lamentablemente para los machos, Vallejo hizo oídos sordos a la demanda de
los asistentes" (P3): Se destaca una idea de "macho" como el hombre acosador y
asechador, exigiendo su derecho sexual.
"Ambos [...] participaron en una sesión de la CONFECH. En ella [...] se criticó
la última propuesta del gobierno" (P5): Se hace una marcada oposición entre las
acciones que realizan los estudiantes y el gobierno. Mientras que el gobierno
"propone", hace esfuerzos por buscar una solución al conflicto, los estudiantes
basan su proceder en la "crítica".
"... aseguró Jackson, quien luego se dio el tiempo de bailar al ritmo de Chico
Trujillo y Los Tres" (P6): Se intenta restar la importancia al carácter político-
ideológico de este acto familiar por la educación, destacando la presencia de
conocidas bandas musicales nacionales. Jackson también deja de lado su misión
como líder para disfrutar.

\subsubsection{Estructuras sutiles}

Por estructuras sutiles podemos entender aquellas ideas que difunde el discurso noticioso y que no se perciben directamente, debido a su sutileza. Son aquellas formas que inciden en el inconsciente del lector o receptor de la noticia. Están directamente relacionadas con el aparato ideológico invisible, con las relaciones de poder que son activadas a partir de la información emitida. En palabras simples, son lo que se entiende como modelos mentales e ideas preconcebidas sobre el otro al que se alude en el texto, desde los discursos de autoridad. Esta dimensión hace referencia a la representación y a la autorepresentación colectiva y, por lo tanto, a "... los conflictos por la conquista o la transformación de los imaginarios" (Abril, 2007: 36).

En este sentido, encontramos que, a través de esta noticia, se hace la distinción clásica del discurso ideologizado (de derecha), donde el relato se organiza por la confrontación polarizada de dos actores: por un lado los estudiantes secundarios y universitarios (ellos, los otros) y por el otro lado el gobierno chileno (nosotros).

Ellos critican, protestan, se movilizan, van a paro, son subversivos (aspectos negativos). Nosotros hacemos propuestas, buscamos soluciones, somos conciliadores (aspectos positivos). Ellos son utópicos, Nosotros somos objetivos. Ellos tienen una líder (Camila Vallejo) que se ajusta a los cánones de belleza occidental, por lo tanto, Nosotros ponemos en duda sus facultades intelectuales. Nosotros dudamos de la capacidad de convocatoria de la causa social y política (educación de calidad, sin lucro, financiada por el estado), apuntando a que los asistentes estaban interesados en ver a la líder por sus atributos físicos. Además, Ellos tienen una líder que los decepciona al no querer "bailar la colita".

Se manifiesta, además, una discriminación etaria: Ellos (los jóvenes) y Nosotros (los adultos). Ellos son idealistas, Nosotros somos serios y responsables. Ellos son inmaduros, Nosotros tenemos la experiencia.

También encontramos muy marcada la presencia del discurso sexista: Camila Vallejo es mujer, por lo tanto, era su deber haber bailado "la colita" y responder a la solicitud del público masculino. Ella es la "mina" del movimiento estudiantil, la "mijita rica", "más rica que el pan con pebre", usa una polera roja (color del comunismo y socialismo) que destaca su "delgada figura" y un "ajustado jeans": cumple con el este- 
reotipo impuesto en occidente de mujer bella, por lo tanto, importa más cómo se ve que su mensaje. Es considerada un mero objeto de deseo.

\section{Conclusiones}

La prensa tradicional escrita en Chile forma parte de la estructura de legitimación y representación ideológica de la clase burguesa dominante (tanto económica como socialmente), aún cuando su público objetivo lector no sean ellos mismos. Y son los valores e imaginarios de esta clase dominante los que se transmiten en las informaciones, por ello, es ésta la realidad que se está construyendo y reproduciendo por medio de las entregas informativas.

El Movimiento Estudiantil 2011 en Chile, al personificar un férreo ataque a las bases del sistema neoliberal, y por ende, al presentarse como opositor al régimen en el que se cimientan los medios de comunicación tradicionales de nuestro país, es tergiversado, discriminado, y criminalizado en las noticias de dichos medios, en las que se destacan sus aspectos negativos.

Del análisis se desprende que, en el diario Las últimas noticias, la estrategia es farandulizar y banalizar al movimiento a través de sus líderes, restándole seriedad y profundidad al análisis de la contingencia nacional y a los problemas sociales, entre ellos un tema tan transcendente como la educación gratuita y de calidad. Se ataca directamente a Camila Vallejo, por medio de construcciones léxicas y alusiones sexistas, tanto explícitas como implícitas en el texto (y que son re-producidas desde el contexto ideológico de los medios). Esto pareciera hasta inconcebible, considerando además que la periodista que redacta la nota es una mujer, y como mínimo, es de esperarse una cierta solidaridad de género.

Pero son otras variables, además del sexo/género, las que entran en juego: edad, apariencia física, militancia política. La intención es individualizar, personalizar al movimiento en una sola figura, así es más fácil derrotarlo y desacreditarlo públicamente $^{18}$. Olvidan que Camila Vallejo es una de los representantes, pero que junto a ellos hay una gran colectividad, un grupo mayoritario de chilenos que demandan equidad y dignidad.

Es por esto, y dado que este estudio se centró en analizar una noticia emblemática, que no se debe desconocer la responsabilidad social del periodista: si bien éste trabaja abocado a una línea editorial del medio que lo contrata (y bajo la supervisión de un editor), no es menos cierto que tiene un deber ético y moral cada vez que redacta una noticia. Tampoco se trata se ingenuidad, o de exigirle al periodismo ser objetivo y neutral. Es sabido que eso nunca es posible. Pero al menos, y en una rigurosidad deontológica, debe buscarse la pluralidad y la honestidad en la labor informativa, evitando la manipulación.

${ }^{18}$ Cabe aquí recordar, por ejemplo, la publicación en Twitter de la Directora Ejecutiva del Fondo del Libro, Tatiana Acuña, quien señaló en medio de las manifestaciones estudiantiles del 04 de agosto de 2011 "Se mata a la perra, se acaba la leva", en directa alusión a Camila Vallejo.Fuente: http://www.cooperativa.cl/ministro-de-cultura-reitero-rechazo-a-dichos -de-funcionaria-contra-camila-vallejo-via-twitter/prontus_nots/2011-08-10/121548.html 
Si la realidad social de los lectores se construye a través de las informaciones que reciben, es de esperar que éstas sean lo más completas y dialógicas posibles, que reconstruyan y re-presenten a todos los actores sociales, que sus imágenes sean equilibradas. Es más, un verdadero ejercicio del periodismo social debiera estar de parte de los oprimidos por el sistema.

La rutina periodística debe superar el miedo al compromiso político: el acceso a la (buena) información es clave en permitir la creación de una sociedad más justa. No se trata solamente de mejorar los vías, sino también de entregar las herramientas para que ésta información pueda ser aprovechada para el desarrollo. Una buena salida son los medios alternativos en internet y la democratización de las redes sociales. Pero eso no basta: se hacen cada día más necesarias la solidaridad, la empatía y la cooperación. Si son los medios de comunicación nuestro reflejo, ¿tiene cada país los medios que merece? ¿Es posible pensar en mejores medios de comunicación? Para que el país mejore, deben mejorar los medios de comunicación y, proporcionalmente, mejorar los periodistas. Hacer carne las buenas intenciones y el profesionalismo, concretizarlos en acciones:

Ni el arte por el arte, ni la información por la información. Buscamos informar para inconformar, para sacudir las comodidades de aquéllos a quienes les sobra y para remover la pasividad de aquéllos a quienes les falta. Las noticias, bien trabajadas, aún sin opinión explícita, sensibilizan sobre estos graves problemas y mueven voluntades para resolverlos (López Vigil, 2005: 141).

Para concluir, cabe preguntarse: ¿Qué credibilidad tiene un medio de comunicación como Las últimas noticias? ¿Hasta qué punto lo dejamos influir en nuestra vida cotidiana? Pero, claro, lo consideremos o no como un agente válido, sigue existiendo. Los medios de comunicación burgueses como éste están ahí, se mantienen en pie, como síntoma, como radiografía a contraluz, evidencia de que tanto la sociedad como los comunicadores están fallando:

LUN utiliza la estrategia de la superficialidad, no ir al fondo. Hoy me utilizan a mí, después puede ser otra persona. Ellos banalizan la información para que la gente vea lo superficial solamente y no lo que sucede realmente en los movimientos. Por ejemplo, cuando pusieron 'Camila Vallejo no quiso mover la colita' ¿Qué nivel periodístico hay ahí? (Camila Vallejo, $2011^{19}$ ).

\section{Referencias}

ABRIL, Gonzalo (2007): Análisis Crítico de textos visuales. Mirar lo que nos mira. Madrid, Síntesis.

ARRUETA, César (2010): ¿Qué realidad construyen los diarios? Una mirada desde el periodismo en contextos de periferia. Buenos Aires, La Crujía.

${ }^{19}$ Entrevista a Camila Vallejo: "Necesitamos un cambio constitucional”. El Ciudadano, N¹09, primera quincena septiembre 2011. Fuente: http://www.elciudadano.cl/2011/10/11/42258/camila-vallejo-necesitamos-un-cambio-constitucional/ 
BERGER, Peter y LUCKMANN, Thomas (2011): La construcción social de la realidad. Buenos Aires, Amorrortu.

CUADRA, Álvaro (2012):" Manifestaciones Estudiantiles en Chile. Cultura de la protesta: Protesta de la cultura". http://www.uarcis.cl/descarga/manifestaciones-estudiantiles.pdf

GARCÉS, Mario (2012): El despertar de la sociedad. Los movimientos sociales en América Latina y Chile. Santiago de Chile, LOM.

KAPUŚCIŃSKI, Ryszard (2003): ¿Acaso los medios reflejan la realidad del mundo?; en: La Prensa ¿Refleja la realidad? Nuevas tecnologías y concentración de medios. Santiago de Chile, Editorial Aún Creemos en los Sueños.

LÓPEZ VIGIL, José Ignacio (2005): "Manual urgente para radialistas apasionados". http://www.radialistas.net/manual_urgente/ManualUrgenteRadialistas.pdf

MATTELART, Armand; PICCINI, Mabel y MATTELART, Michèle (1976): Los medios de comunicación de masas. La ideología de la prensa liberal en Chile. Buenos Aires, El Cid Editor.

OESTERHELD, Héctor Germán (2011): El Eternauta: 1957-2007, 50 años. Buenos Aires, Doeditores.

OSSA, Carlos (2003): Saberes académicos y modernización. Bogotá, Grupo Editorial Norma.

RENKEMA, Jan (1999): Introducción a los estudios sobre el discurso. Barcelona, Gedisa.

RODRIGO ALSINA, Miquel (2005): La construcción de la noticia. Nueva edición revisada y ampliada. Barcelona, Paidós.

SANTANDER, Pedro (2009): "Por qué, para qué y cómo hacer Análisis de Discurso de los medios de comunicación"; en SANTANDER, Pedro: Analizando los medios y la comunicación: teoría y métodos. Valparaíso, Pontificia Universidad Católica de Valparaíso, Ediciones Universitarias de Valparaíso,

SCHANIDER, Romina y ZAROWSKY, Mariano (2007): Comunicación para principiantes. Buenos Aires, Era Naciente.

SERRANO, Pascual (2011): El periodismo es noticia. Tendencias sobre comunicación en el siglo XXI. Quito, CIESPAL, Editorial Quipus.

VALLEJO, Camila (2012): Podemos cambiar el mundo. Santiago de Chile, Ocean Sur.

VAN DIJK, Teun (2003): Dominación étnica y racismo discursivo en España y América Latina. Barcelona, Gedisa.

VAN DIJK, Teun (1997): Racismo y Análisis Crítico de los Medios. Barcelona, Paidós.

VAN DIJK, Teun (1990): La noticia como discurso. Comprensión, estructura y producción de la información. Barcelona, Paidós. 
VARELA, Francisco (2005): "El círculo creativo. Esbozo historiconatural de la reflexividad"; en WATZLAWICK, Paul: La realidad inventada ¿cómo sabemos lo que creemos saber? Barcelona, Gedisa.

VÁZQUEZ MEDEL, Manuel (1998): "La prensa escrita y la construcción social de la realidad". GITTCUS Publicación digital del Grupo de Investigación en Teoría y Tecnología de la Comunicación de la Universidad de Sevilla: http://huespedes.cica.es/aliens/gittcus/licsr.htm

VERA, Héctor (2008): "Estrategias de construcción de noticias"; en BROWNE, Rodrigo; del VALLE, Carlos; MAYORGA, Javier; NITRIHUAL, Luís y SILVA, Víctor: Contrapuntos y Entrelíneas sobre Cultura, Comunicación y Discurso. Temuco, Ediciones Universidad de La Frontera.

\section{Anexos}
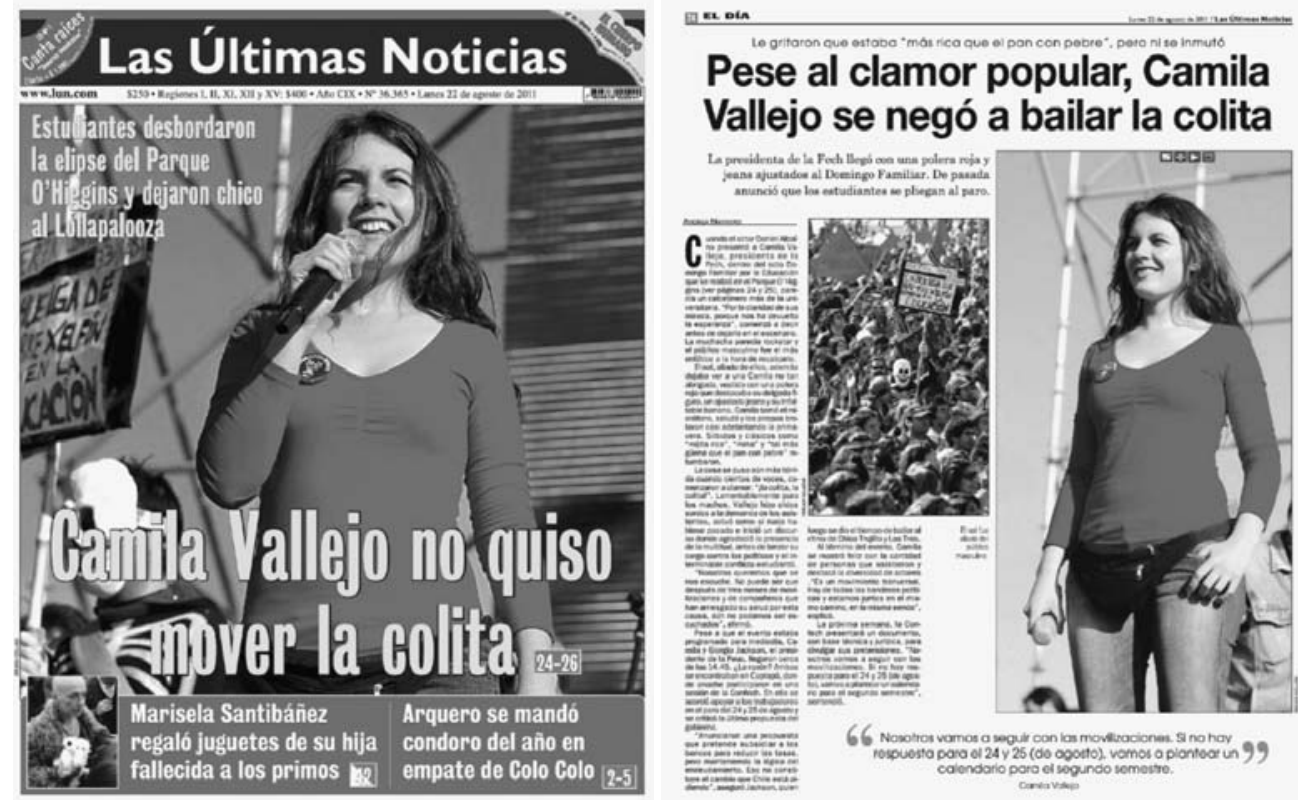